International Journal of Current Advanced Research

ISSN: O: 2319-6475, ISSN: P: 2319 - 6505, Impact Factor: SJIF: 5.995

Available Online at www.journalijcar.org

Volume 6; Issue 4; April 2017; Page No. 3312-3315

DOI: http://dx.doi.org/10.24327/ijcar.2017.3315.0259

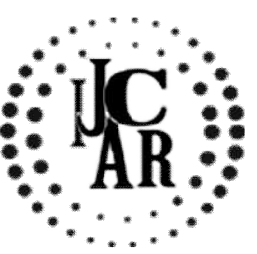

Research Article

\title{
KNOWLEDGE ABOUT ORAL HYGIENE \& BRUSHING TECHNIQUES IN CHILDREN
}

\section{Abijeth B and Kanthaswamy A.C}

Saveetha Dental College\& Hospitals, 162, P.H.Road, Chennai - 600077

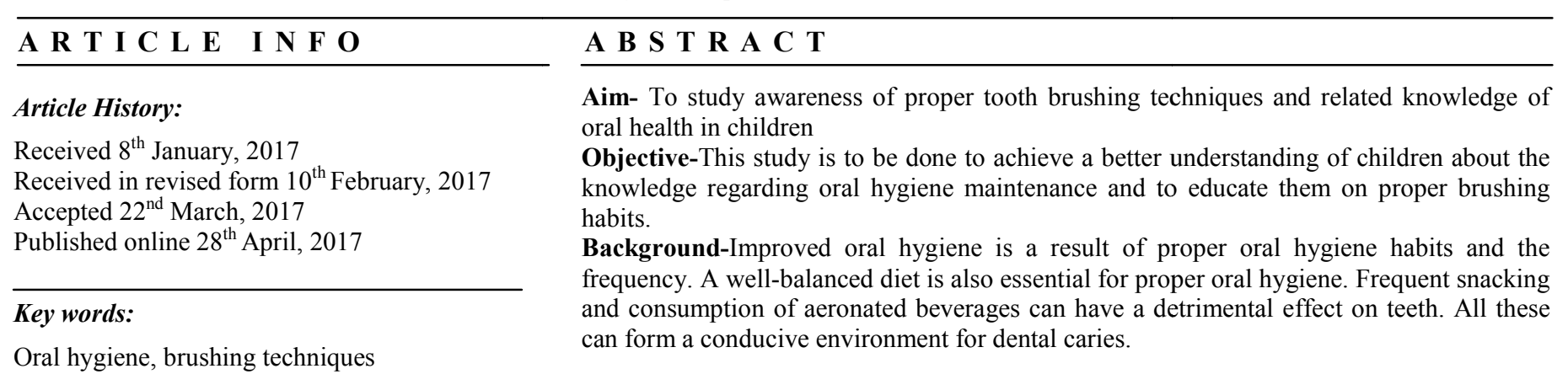

Copyright $₫ 2017$ Abijeth B and Kanthaswamy A.C. This is an open access article distributed under the Creative Commons Attribution License, which permits unrestricted use, distribution, and reproduction in any medium, provided the original work is properly cited.

\section{INTRODUCTION}

Oral hygiene is the practice of keeping the mouth and teeth clean to prevent dental problems, most commonly, dental cavities, gingivitis, periodontal diseases and bad breath. ${ }^{[1]}$ Oral health is fundamental to general health and well-being. A healthy mouth enables an individual to talk, eat and socialise without experiencing active disease, discomfort or embarrassment. ${ }^{[2]}$ Oral diseases adversely affect concentration, interpersonal relationship, and productivity due to the intricate relationship between oral health and general health. ${ }^{[3]}$ The two most common oral diseases are dental caries and periodontal disease and they often begin in childhood. These could be attributed to several factors mainly lack of oral health awareness and over consumption of refined carbohydrate ${ }^{[2]}$ People living in developing countries, and concomitantly of lower socio- economic status have a lacunae in oral health awareness mirrored in their practice of oral hygiene habits. ${ }^{[4]}$ The incidence of dental caries in school children has been found to be high in children who have poor maintenance of oral hygiene. ${ }^{[5]}$ According to recent surveys conducted, an increase in cavities in preschoolers has been seen. The amount of decay seen is so deleterious that there is a need for deep sedation and general anaesthesia as children are unlikely to sit for extensive treatments. ${ }^{[3]}$ Children who suffer from poor oral health are 12 times more likely to have restricted-activity days than those who do notice. ${ }^{[2]}$ Tooth Brushing and flossing are practices to maintaingood dental health, along with regular dental visits. $^{[4]}$

*Corresponding author: Abijeth B

Saveetha Dental College\& Hospitals, 162, P.H.Road, Chennai $-600077$
Tooth brushing is the mechanical removal of plaque and debris, hence preventing the development of dental caries and periodontal infections. Tooth brushing techniques that are learnt during the first five years of life is the basis for maintaining good oral hygiene in the later years. Children's tooth brushing habits were acquired from their parents knowledge about oral health. ${ }^{[5]}$ As children spend much time in school, teachers can also assist with dental health education programs. ${ }^{[2]}$ So this survey was conducted to Assess the knowledge, attitude and behaviour of children towards oral hygiene and brushing techniques in chennai.

\section{MATERIALS AND METHODS}

The study sample consisted of 370 private schoolchildren in and around Moggappair, Chennai. A self designedpretested questionnaire was applied among the students and questions regarding knowledge aboutthe child's methods of brushing, type of toothpaste used for cleaning teeth and frequency was asked. Attitude towards oral hygiene and practice of brushing techniques and visit to dentist were enquired.The students who participated were from 6-12th standard who were from middle class and upper middle class status of the society. They were selected, in order to aid their understanding of the questionnaire. The study was conducted after getting proper permission from the school management. The study involved questions which includes personal oral hygiene like frequency of brushing,cleaning aids used etc. Data collected from the school children were compiled and then analysed statistically.

\section{RESULTS}

According to the statistical analysis, different results were obtained and they were charted with respect to each question. 
When asked about the liking of their toothpaste, $86 \%$ of the children said yes whereas $14 \%$ of the children did not like the taste of it.(Fig 1)

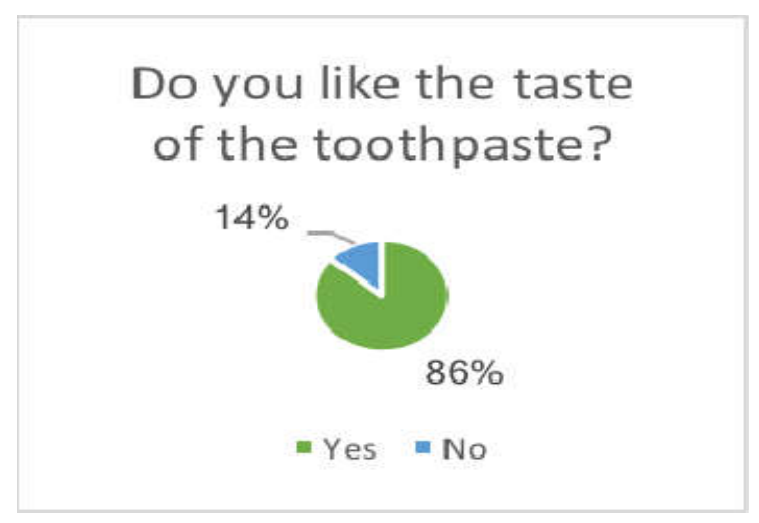

Fig 1

When asked how many times you brushed your teeth $73 \%$ of the children brushed once a day, $24 \%$ of the children brushed twice a day and $3 \%$ of the children brushed thrice a day. (Fig 2)

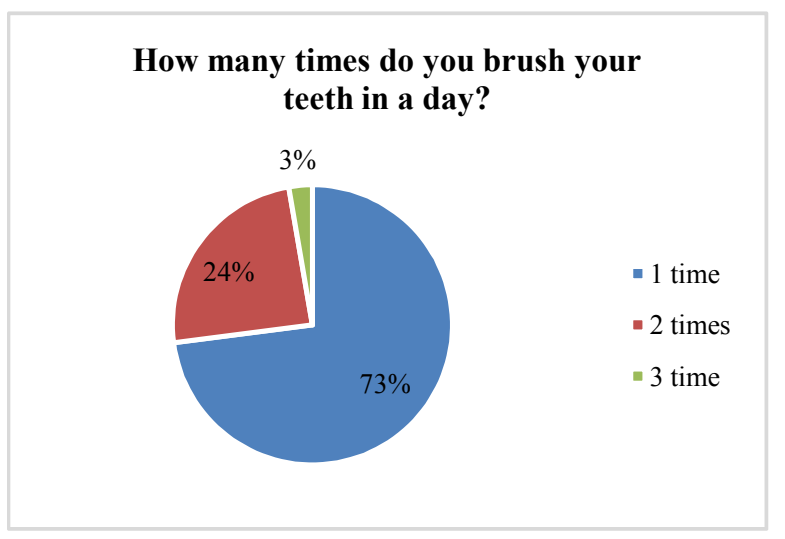

Fig 2

When questioned regarding the rinsing of the mouth after every meal $57 \%$ of the children said yes for rinsing and $43 \%$ of the children responded no for it. (Fig 3)

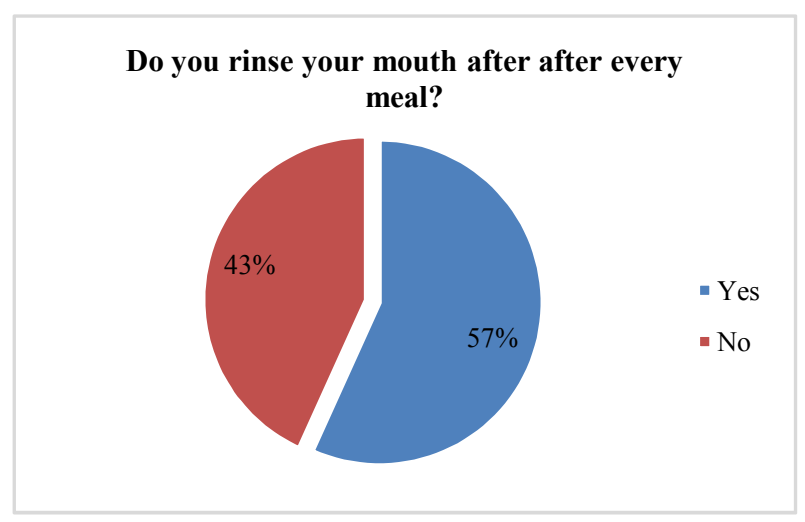

Fig 3

The children were questioned when do they feel it's important to brush their teeth and $57 \%$ responded that it's important to brush in the morning while $8 \%$ responded that it's important to brush in the night and 35\% responded that it's important to brush both in the morning and in the night.(Fig 4)

The children were enquirer about the brushing technique and how do they perform their day to day brushing.

\section{When do you think its Most important to brush teeth?}

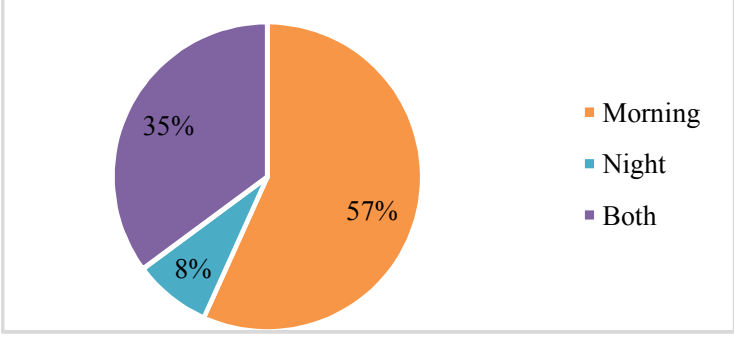

Fig 4

$41 \%$ of the children performed brushing in horizontal manner, $27 \%$ of the children performed brushing in all directions, $19 \%$ of the children performed brushing in vertical manner and $13 \%$ of the children performed brushing in circular motions. (Fig 5)

\section{How do you brush your teeth?}

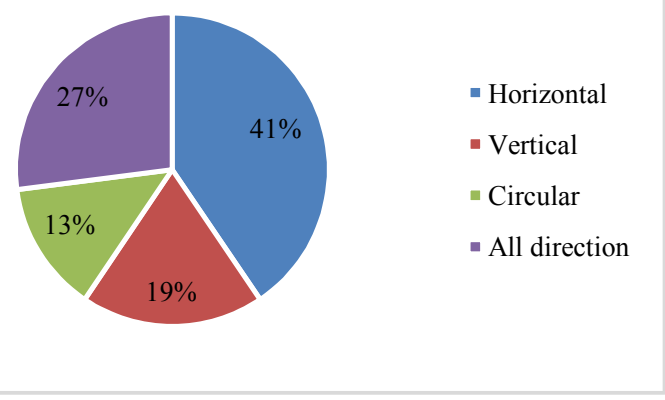

Fig 5

The children were asked whether they liked to brush their teeth. $84 \%$ of the children responded yes while $16 \%$ of the children responded no.(Fig 6) Reasons where enquired why do they perform brushing and why they do not.The children came up with varied reasons and they are $-36 \%$ of them brushed to have a clean teeth while $26 \%$ do it to have a bright teeth. $16 \%$ of them performed brushing to get rid of their foul breath. $13 \%$ of them perform brushing as a prevention of caries and $6 \%$ as a prevention of bleeding gums.3\% of them perform brushing to set example for others.(Fig 7) Reasons for not brushing included bleeding of gums for $32 \%$ of the individuals, $30 \%$ of the individuals do not like the smell of their tooth paste used, $13 \%$ of the children gave an excuse of forget to brush their teeth, $12 \%$ of the children had no enough money to afford toothbrush and toothpaste, $8 \%$ had no time while $5 \%$ of them did not brush as none in their family doesn't do that.(Fig 8)

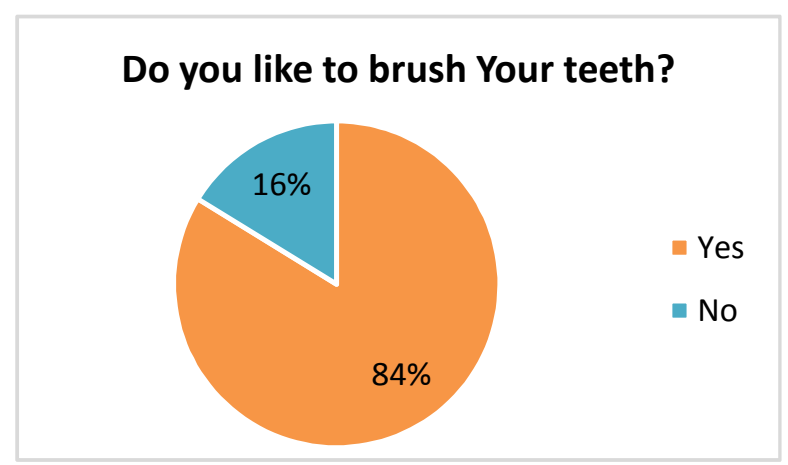

Fig 6 


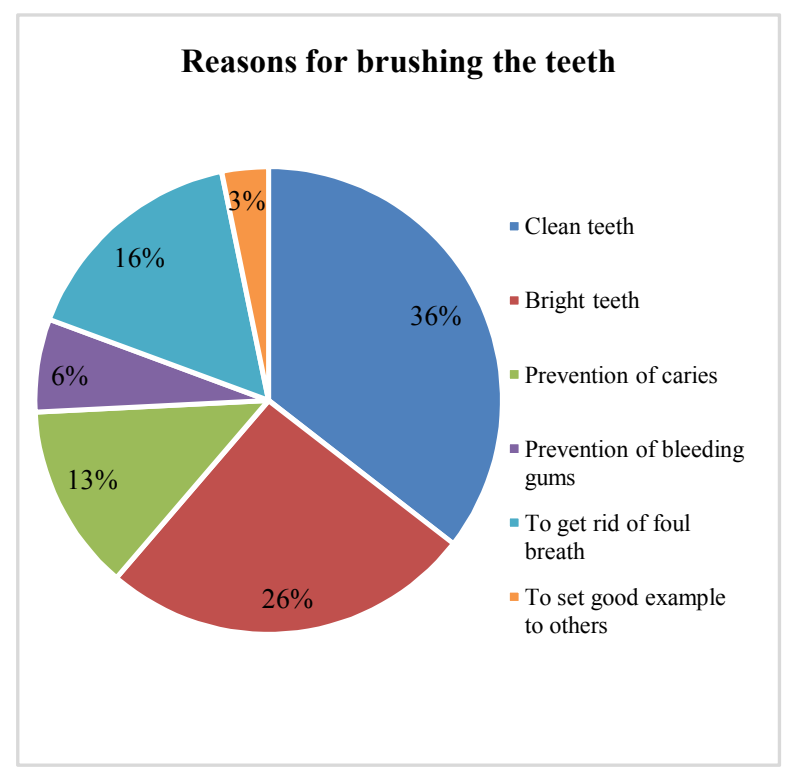

Fig 7

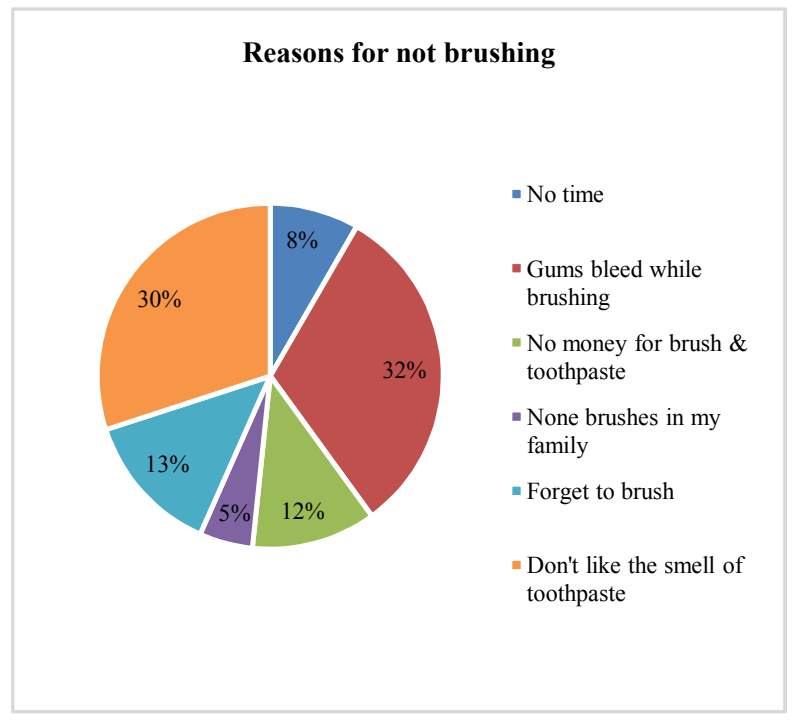

Fig 8

The children were asked about the usage of mouthwash where $30 \%$ of the children have the habit of using mouthwashes whereas $70 \%$ of the children said they do not use mouthwashes. (Fig 9)

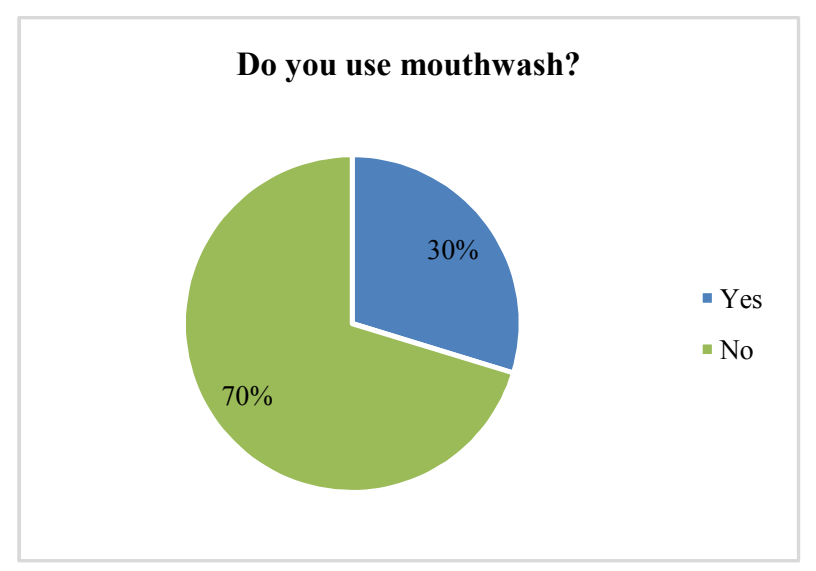

Fig 9

Individuals were enquired about the use of floss where $22 \%$ of them used floss on a daily basis whereas $78 \%$ of them did not use the floss.(Fig 10)

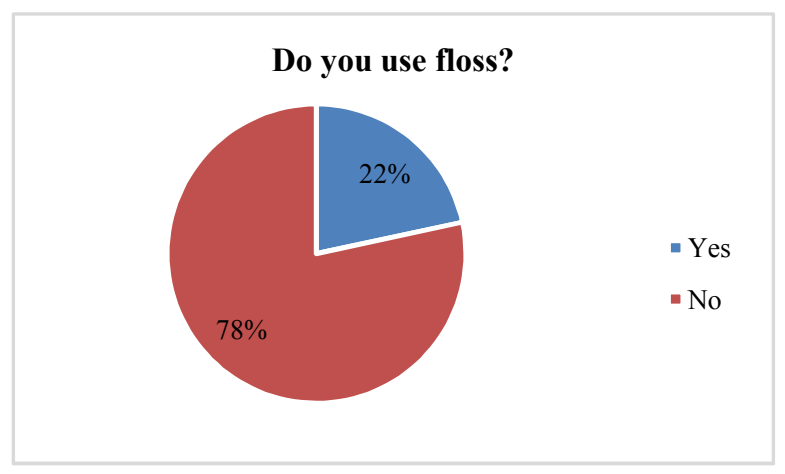

Fig 10

The children were questioned about tongue cleaning habit where $43 \%$ responded with yes and $57 \%$ responded with no. (Fig 11)

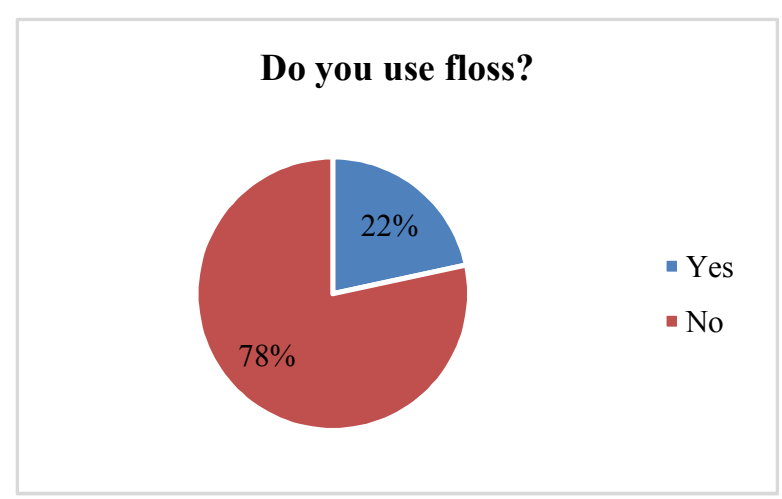

Fig 11

The children were questioned about the kind of toothpaste they use and of which $49 \%$ used paste, $43 \%$ used gel and $8 \%$ used powder.(Fig12)

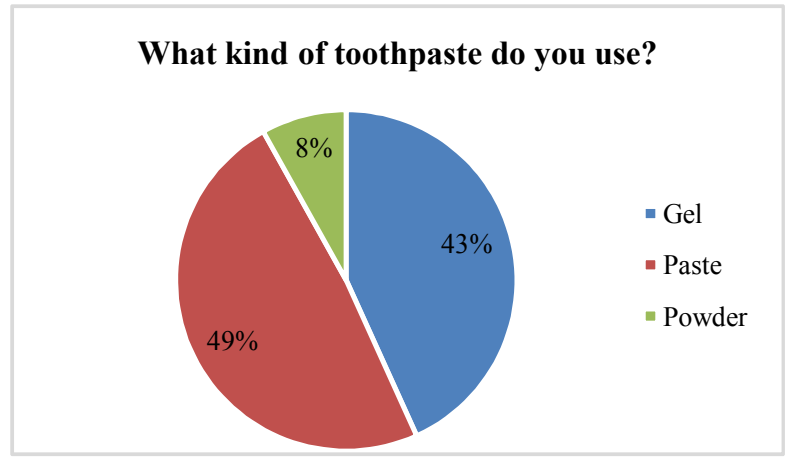

Fig 12

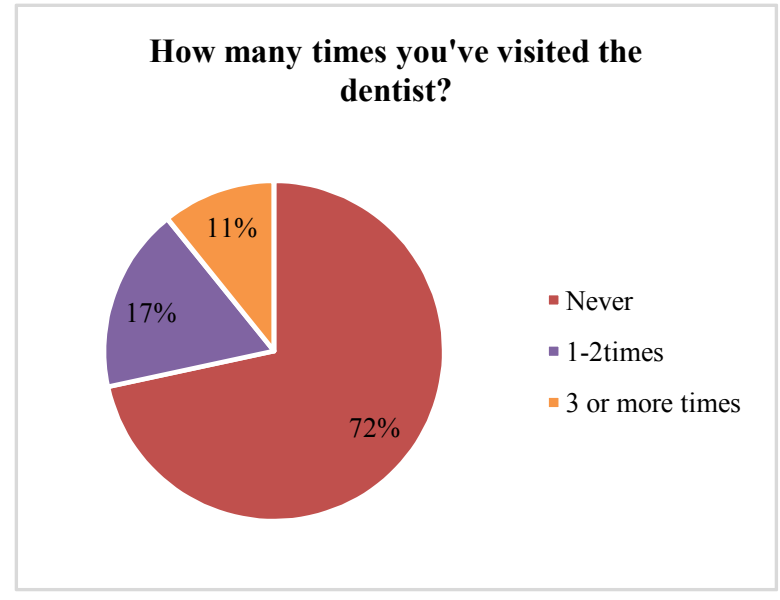

Fig 13 
The children were enquired about their visit to the dental office to which $72 \%$ of the individuals had never visited the dental office, $17 \%$ of them had one or two visits while $11 \%$ of them had visited the dental office three or more times. (Fig 13)

\section{DISCUSSION}

Harikiran et alin his study showed that $58.9 \%$ brushed their teeth once a day while $38.5 \%$ brushed twice daily. ${ }^{[1]}$ Brushing of teeth at least twice a day, in the morning before breakfast and at night after last drink, is an important habit to maintain. According to Attin $\mathrm{T}$ et al. most patients do not achieve sufficient plaque removal. Therefore, brushing of teeth twice daily is recommended in order to improve plaque control. Reportedly, $24 \%$ of the children brushed twice a day while $73 \%$ of the children in our study brushed once a day. Punitha et al showed that $29.62 \%$ rinse their mouth always after having food or drink. ${ }^{[1]}$ Mouth rinsing as a formal practice has its reference credited to Chinese medicine about $2700 \mathrm{BC}$, for the treatment of diseases of the gums. It is essential to practice mouth rinsing after every meal, to prevent food lodgment which provides a nidus for bacterial growth. ${ }^{[3]}$ In our study $57 \%$ rinse their mouth after having food.According to Frandsen A, who reported that no particular method of brushing is superior to one another. Also, over $90 \%$ of people employed their own tooth brushing method using vigorous horizontal, vertical, and circular movements. ${ }^{[3]}$ In our study $41 \%$ of the individuals brushed in a horizontal manner while $27 \%$ performed brushing in all directions. Hence, there is a general lack of knowledge regarding the method of brushing amongst children.Flossing and mouth washing is an important attribute to oral hygiene maintenance, and only $30 \%$ of the individual use mouthwash and $22 \%$ of the individual perform flossing. This contradicts a previous study conducted by Walsh MM in San Francisco where $75 \%$ claimed to have used dental floss, at least once a day. However, in Saudi Arabia only $2.3 \%$ of the study population used dental floss and in South India, floss was reported to be the least used cleaning aid. More than half (54\%) of the American children were flossing regularly in comparison to the $15 \%$ of the Indian children who flossed frequently. This could be due to lack of awareness regarding the cleaning of all the surfaces of teeth with dental floss. It is imperative to educate the parents and children in our population regarding the importance and the technique of using the floss.

Tongue cleaning was reported to be done by $43 \%$ of the individuals. It has been reported that tongue cleaning done by a toothbrush or a tongue cleaner provides an efficient reduction in streptococcus mutant count and a significant reduction in plaque levels. ${ }^{[3]}$ In our study $72 \%$ of the individuals haven't visited the dental office even once. This maybe due to fear of dental setup, lack of tooth ache or lack of parental encouragement. We also agree with the fact stated by Jalevik et al in 1999 that lack of parents regular dental attendance might be reflected in children's dental attitude.
The behavior displayed by the parents might also be the cause of lack of attendance regarding thevisit to the dentist. Barker and Horton showed that delay in seeking dental care could be attributed to other factors like parental belief and practices, lack of economical resources and lack of accessibility to dental services. They also showed that parents played a vital role $^{[6]}$

A statistically significant improvement in oral hygiene shows that in childhood is necessary continuous motivation and remotivation, in order to maintain good oral hygiene.Oral health education and training were effective in establishing good oral health habits among school children and also in enhancing the knowledge of their parents about good oral health. ${ }^{[7]}$

\section{CONCLUSION}

Results of current study shows that the knowledge attitude practice about oral hygiene among school children was not satisfactory and has to improved significantly. Systematic community-oriented oral health promotion programs are needed to improve oral health knowledge attitude and practice of the school students.

\section{Reference}

1. "Health topics: Oral health". World Health Organization (WHO). Retrieved 6 March 2015

2. Vishnu G Ashok, Krishnaprasad C. A study on oral hygiene among school children in a rural area of Tamilnadu. International Journal of Contemporary Medical Research 2016;3(9):2798-2799.

3. Priya M, Kanagharekha Devdas1, Deepti Amarlal, Venkatachalapathy A. Oral health attitudes, knowledge and practice among school children in Chennai, India. Journal of education and Ethics in Dentistry JanuaryJune 2013 • Vol. 3 • Issue 1

4. Winnier JJ, Parmar A, Mehta S, Bambal K, Bhatia R Oral Hygiene Maintenance in Children- A Survey of Parental Awareness. Int $J$ Oral Health Med Restaurant 2015;2(4): 15 .

5. Mohammed Ahad1, Gheena.S. Awareness of Tooth Brushing Techniques and Proper Oral Hygiene among School Children.Mohammed Ahad et all J. Pharm. Sci. \& Res. Vol. 7(6), 2015, 367-372

6. Aishwary.A.S And Dr.Deepa Gurunathan Oral Health Maintenance In Children With Self Brushing And Parents Guidence: A Pilot Study. Int J Pharm Bio Sci 2015 Oct; 6(4): (B) 535 - 543

7. Satish Vishwanathiah. Knowledge, Attitude and oral health practices of school children in Davangere. International journal of Clinical pediatric dentistry, April -June 2016;9(2):172-176

8. Liliya Doichinova, Nadezhda Mitova. Assessment of Oral Hygiene Habits In Children 6 TO 12 Years. Journal of Imab - Annual Proceeding (Scientific Papers) 2014, vol. 20, issue 5 